\title{
Tristetraprolin regulates the decay of the hypoxia-induced vascular endothelial growth factor mRNA in ARPE-19 cells
}

\author{
JINHYUN RYU ${ }^{1}$, HYEMIN SEONG ${ }^{1}$, NAL AE YOON ${ }^{1}$, SEONG WOOK SEO ${ }^{2,3}$, JEONG WOO PARK ${ }^{4}$, \\ SANG SOO KANG ${ }^{1}$, JONG MOON PARK ${ }^{2,3}$ and YONG SEOP HAN ${ }^{2,3}$ \\ Departments of ${ }^{1}$ Anatomy and Convergence Medical Science and ${ }^{2}$ Ophthalmology, Institute of Health Sciences, \\ School of Medicine, Gyeongsang National University, Jinju, Gyeongnam 52727; ${ }^{3}$ Department of Ophthalmology, \\ Gyeongsang National University Hospital, Jinju, Gyeongnam 52727; ${ }^{4}$ Department of Biological Sciences, \\ University of Ulsan, Ulsan 44610, Republic of Korea
}

Received September 17, 2015; Accepted September 27, 2016

DOI: $10.3892 / \mathrm{mmr} .2016 .5890$

\begin{abstract}
The aim of the present study was to investigate the effects of tristetraprolin (TTP) on the vascular endothelial growth factor (VEGF) mRNA and protein expression levels in retinal pigment epithelial cells under hypoxic conditions, and to consider the possibility of using TTP as a novel treatment tool for neovascular age-related macular degeneration (AMD). Overexpression of TTP reduced the expression and secretion levels of VEGF in ARPE-19 cells under hypoxic conditions. TTP destabilized the VEGF mRNA by binding to adenosine and uridine-rich elements regions in its 3'-untranslated region. Furthermore, conditioned medium (CM) from TTP-overexpressing ARPE-19 cells suppressed the tube formation in human umbilical vein endothelial cells compared with hypoxic CM. These findings indicate that regulation of TTP expression may be a promising therapeutic tool for neovascular AMD, however, further research is required.
\end{abstract}

\section{Introduction}

Age-related macular degeneration (AMD) is a leading cause of blindness for those over the age of 60 , affecting millions of people. The disease is associated with impaired sight, but also with emotional distress, depression and anxiety (1). New vessels generated by neovascularization usually undergo repeated regeneration, which leads to bleeding and vessel destruction due to stress as a result of increased permeability. Certain pathways associated with neovascularization are

Correspondence to: Professor Yong Seop Han, Department of Ophthalmology, Institute of Health Sciences, School of Medicine, Gyeongsang National University, Jinju-Daero 816 Beon-gil 15, Jinju, Gyeongnam 52727, Republic of Korea

E-mail: medcabin@naver.com

Key words: ARPE-19 cells, hypoxia, neovascular age-related macular degeneration, tristetraprolin, vascular endothelial growth factor linked to increased expression levels of vascular endothelial growth factor (VEGF) (2-4). Thus, VEGF is a major component of the neovascularization process.

VEGF-A, also known as VEGF, belongs to the cysteine-knot superfamily of growth factors. The characteristics of VEGF are determined by a cysteine residue $(5,6)$. The anti-angiogenic effects of monoclonal anti-VEGF antibodies, including ranibizumab and bevacizumab have been confirmed by previous studies (7-10). However, multiple injections are required and certain patients do not respond to intravitreal anti-VEGF antibody administration (11-14). Recently, multiple efforts have been made to overcome these limitations (15-18).

VEGF transcription is activated by growth factors and hypoxia (19). The 3'-untranslated regions (3'-UTRs) of resulting transcripts contain adenosine and uridine rich elements (AREs), which determine mRNA stability. ARE-mediated post-transcriptional regulation is facilitated by trans-acting ARE-binding proteins, which form stable complexes with the 3'-UTR and regulate the decay of VEGF mRNA $(20,21)$. Therefore, the relative abundance of these ARE-binding proteins determines the level of VEGF transcripts $(22,23)$. Tristetraprolin (TTP) is a $34 \mathrm{kDa}$ member of the $\mathrm{CCCH}$ class of tandem zinc finger proteins (24-26). TTP was first demonstrated to interact with AREs in mRNAs, and its list of known and likely targets continues to grow. However, to the best of our knowledge, the effects of TTP in retinal pigment epithelial (RPE) cells have not been examined.

The aims of the present study were to investigate the effects of TTP on VEGF mRNA and protein expression levels in ARPE-19 cells under hypoxic conditions and to consider the possibility that TTP may be useful as a novel treatment tool for neovascular AMD (nAMD).

\section{Materials and methods}

Cell culture and treatment. ARPE-19 cells (American Type Culture Collection, Manassas, VA, USA) were cultured in Dulbecco's modified Eagle's medium/Nutrient Mixture F-12 (DMEM/F12; Gibco; Thermo Fisher Scientific, Inc., Waltham, MA, USA) supplemented with $10 \%$ fetal bovine serum (FBS; Gibco; Thermo Fisher Scientific, Inc.), $100 \mu \mathrm{g} / \mathrm{ml}$ streptomycin 
and $100 \mathrm{U} / \mathrm{ml}$ penicillin (Gibco; Thermo Fisher Scientific, Inc.). The cells were maintained at $37^{\circ} \mathrm{C}$ in an atmosphere containing $5 \% \mathrm{CO}_{2}$.

Plasmids, transfection, and hypoxic conditions. To overexpress TTP, ARPE-19 cells were transfected with a pcDNA6/V5-HisA vector containing the TTP coding region (pcDNA6/V5-TTP; Invitrogen; Thermo Fisher Scientific, Inc.) (27) using TurboFect ${ }^{\mathrm{TM}}$ in vitro transfection reagent (Thermo Fisher Scientific, Inc.). The ARPE-19 cells were incubated at $37^{\circ} \mathrm{C}$ in $1 \% \mathrm{O}_{2}$ and $5 \% \mathrm{CO}_{2}$ to mimic hypoxia.

Reverse transcription-polymerase chain reaction (RT-PCR). Total RNA was extracted using TRIzol reagent (Invitrogen; Thermo Fisher Scientific, Inc.) following the manufacturer's protocols. Total RNA $(1 \mu \mathrm{g})$ was used for cDNA synthesis using an iCycler thermocycler (Bio-Rad Laboratories, Inc., Hercules, CA, USA). RT-PCR was performed using rTaq polymerase (Elpis Biotech, Daejeon, Korea). VEGF cDNA amplification conditions were as follows: 30 cycles of $94^{\circ} \mathrm{C}$ for $30 \mathrm{sec}, 55^{\circ} \mathrm{C}$ for $30 \mathrm{sec}$ and $72^{\circ} \mathrm{C}$ for $1 \mathrm{~min}$. hGAPDH cDNA amplification conditions were as follows: 20 cycles of $94^{\circ} \mathrm{C}$ for $30 \mathrm{sec}, 55^{\circ} \mathrm{C}$ for $30 \mathrm{sec}$ and $72^{\circ} \mathrm{C}$ for $1 \mathrm{~min}$. The primers were synthesized on the basis of the human TTP, VEGF, and hGAPDH cDNA sequences in the National Center for Biotechnology Information data bank. The sequences of the primers used for PCR were as follows: Forward, 5'-AGG CCAATCGCCACCCCAAA-3' and reverse, 5'-GTGCCA GGGGCAGCAGAGAA-3' for TTP; forward, 5'-GTGGAC ATCTTCCAGGAGTA-3' and reverse, 5'-GTGCTGTAGGAA GCTCATCT-3' for VEGF; and forward, 5'-AGCTGAACG GGAAGCTCACT-3' and reverse, 5'-TGCTGTAGCCAAATT CGTTG-3' for hGAPDH (Bioneer Corporation, Daejeon, Korea).

Quantitative PCR (qPCR). For RNA kinetic analysis, the quantity of VEGF mRNA was assessed in the presence of actinomycin D (Sigma-Aldrich; Merck Millipore, Darmstadt, Germany) using qPCR. The reactions were performed using $\mathrm{EvaGreen}^{\circledR}$ qPCR Master mix (Applied Biological Materials Inc., Richmond, BC, Canada) and a LightCycler 480 instrument II (Roche Applied Science, Madison, WI, USA). VEGF and hGAPDH cDNA amplification conditions were as follows: $95^{\circ} \mathrm{C}$ for $30 \mathrm{sec}, 60^{\circ} \mathrm{C}$ for $30 \mathrm{sec}$ and $72^{\circ} \mathrm{C}$ for $30 \mathrm{sec}$ for 45 cycles. The results were analyzed using melting curves and agarose gel electrophoresis. The PCR primer pairs were as follows: Forward, 5'-CCCCATCCCTGTGGGCCTTG-3' and reverse, 5'-ACCGCCTCGGCTTGTCACAT-3' for VEGF; and forward, 5'-GCACCCCTGGCCAAGGTCAT-3' and reverse 5'-ACGCCACAGTTTCCCGGAGG-3' for hGAPDH (Bioneer Corporation). Relative quantification of gene expression was analyzed using the $2-\Delta \Delta \mathrm{Cq}$ method using GAPDH as the endogenous control (28).

Western blotting. Cells were harvested, centrifuged at $890 \times \mathrm{g}$ for $1 \mathrm{~min}$, and lysed in lysis buffer [50 $\mathrm{mM}$ Tris-Cl (pH 8.0; Amresco LLC, Solon, OH, USA), $150 \mathrm{mM} \mathrm{NaCl}$ (Amresco LLC), 0.1\% SDS (Amresco LLC), 0.02\% sodium azide (Amresco LLC), 1\% NP-40 (Sigma-Aldrich; Merck Millipore), $0.5 \%$ sodium deoxycholate (Sigma-Aldrich;
Merck Millipore) and proteinase inhibitor cocktail (phenylmethylsulphonyl fluoride, $100 \mu \mathrm{g} / \mathrm{ml}$; aprotinin, $1 \mu \mathrm{g} / \mathrm{ml}$; leupeptin, $0.5 \mu \mathrm{g} / \mathrm{ml}$; Roche Applied Science)]. Total protein concentration was determined using a bicinchoninic acid protein assay system (Pierce Biotechnology, Inc., Rockford, IL, USA). Equivalent quantities of total protein (20-30 $\mu \mathrm{g})$ were separated by SDS-PAGE using 10-15\% polyacrylamide gel, and then transferred to a nitrocellulose membrane (Whatman; GE Healthcare Life Sciences, Chalfont, UK) using a semi-dry transfer apparatus (Bio-Rad Laboratories, Inc.) submerged in transfer buffer $(25 \mathrm{mM}$ Tris, pH 8.3, $192 \mathrm{mM}$ glycine, and 20\% methanol). The membrane was blocked with $5 \%$ skimmed milk in $0.1 \%$ Tween-20/Tris-buffered saline (TBST) and incubated with with the following primary antibodies: Anti-TTP (T5327; 1:1,000; Sigma-Aldrich; Merck Millipore), anti-VEGF (ab46154; 1:1,000; Abcam, Cambridge, UK) or anti- $\beta$-actin (A5441; 1:10,000; Sigma-Aldrich; Merck Millipore) antibodies at $4^{\circ} \mathrm{C}$ overnight. Subsequently, the blots were washed in TBST and incubated with goat anti-rabbit (cat. no. 31430) and goat anti-mouse (cat. no. 31460) immunoglobulin G secondary antibodies (1:10,000; Thermo Fisher Scientific, Inc.) for $45 \mathrm{~min}$. Immunoreactivity was detected by enhanced chemiluminescence (Advansta, Inc., Menlo Park, CA, USA) and images were captured using a LAS 4000 Bioimager (Fujifilm Holdings Corporation, Tokyo, Japan).

Enzyme-linked immunosorbent assay (ELISA). ARPE-19 cells were plated onto 6-well cell culture plates at a density of $5 \times 10^{4}$ cells/well. The DMEM/F12 was supplemented with $1 \% \mathrm{FBS}, 100 \mathrm{U} / \mathrm{ml}$ penicillin, and $100 \mu \mathrm{g} / \mathrm{ml}$ streptomycin. VEGF secretion levels were measured using the Human VEGF-ELISA Research-Use-Only kit (KHG0111) from Invitrogen (Thermo Fisher Scientific, Inc.), according to the manufacturer's protocols.

Luciferase assay. A luciferase assay was performed to determine whether the 3'-UTR of the VEGF mRNA is required for TTP-mediated destabilization. ARPE-19 cells were co-transfected with designated constructs, such as psiCHECK-VEGF 3'-UTR constructs and pcDNA6/V5-TTP using TurboFect ${ }^{\mathrm{TM}}$ in vitro transfection reagent (Thermo Fisher Scientific, Inc.). The transfected cells were lysed with lysis buffer (Promega Corporation, Madison, WI, USA) and mixed with luciferase assay reagent (Promega Corporation) and the chemiluminescent signal was measured using the Infinite 200 PRO system (Tecan Group, Ltd., Mannedorf, Switzerland). Firefly luciferase was normalized to Renilla luciferase in each sample. All luciferase assays reported here represent at least three independent experiments, each consisting of three wells per transfection.

Electrophoretic mobility shift assay (EMSA). The biotinylated RNA probes for the wild-type (WT) VEGF (5'-GGUACU UAUUUAAUAGCCCUUUUUAAUUAGAAAUUAAAACAG UUAAUUUAAUUAA-3') and mutant (mut-VEGF-EMSA; 5'-GGUACUUAGGUAAUAGCCCUUUUUAAUUAGAAA UUAAAACAGUUAAGGUAAUUAA-3') were synthesized by Samchully Pharm Co. (Seoul, Korea) as described previously (23). In the mutant (MuT) RNA probes, which were 
A

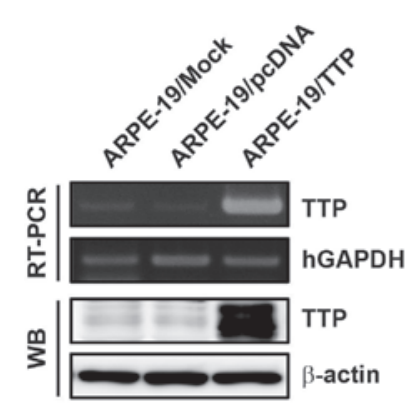

$\mathbf{B}$

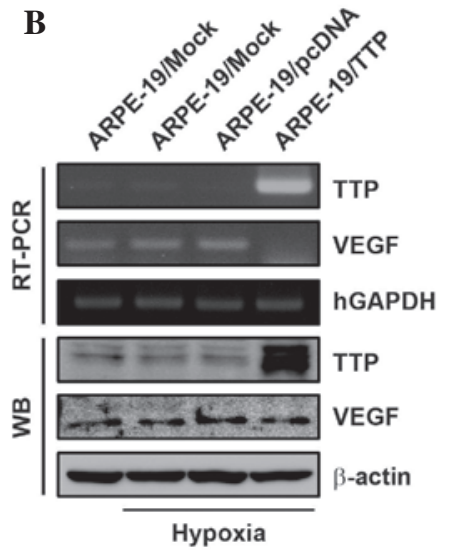

C

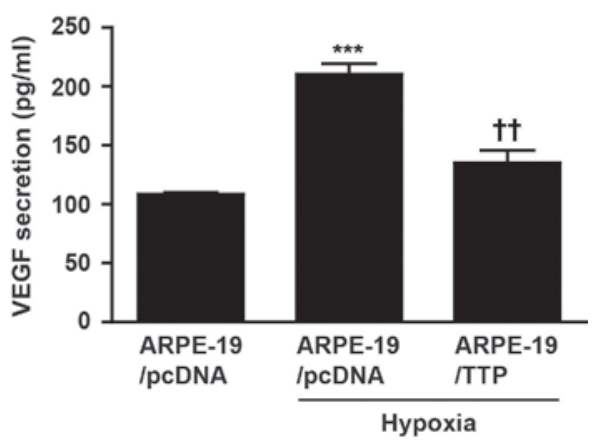

Figure 1. Overexpression of TTP reduces the expression and secretion levels of hypoxia-induced VEGF. ARPE-19 cells were transfected with the pcDNA6/V5-TTP vector (ARPE-19/TTP) or empty pcDNA6/V5 vector (ARPE-19/pcDNA). The cells were incubated at $37^{\circ} \mathrm{C}$ in $1 \% \mathrm{O}_{2}$ and $5 \% \mathrm{CO}_{2}$ to mimic hypoxia. (A and B) The expression levels of TTP and VEGF under normoxic and hypoxic conditions were determined by RT-PCR and WB. The expression levels of hGAPDH and $\beta$-actin served as loading controls. (C) The levels of secreted VEGF were assessed by enzyme-linked immunosorbent assay. Data are presented as the mean \pm standard error of the mean of three independent experiments. ${ }^{* * * *} \mathrm{P}<0.001 \mathrm{vs}$. ARPE-19/pcDNA under normoxia and ${ }^{\dagger} \mathrm{P}<0.01$ vs. ARPE-19/pcDNA under hypoxia. TTP, tristetraprolin; VEGF, vascular endothelial growth factor; RT-PCR, reverse trancription-polymerase chain reaction; WB, western blotting.

A

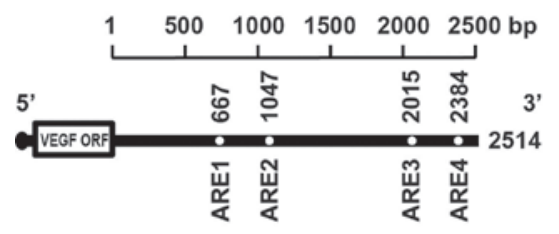

$\mathbf{B}$

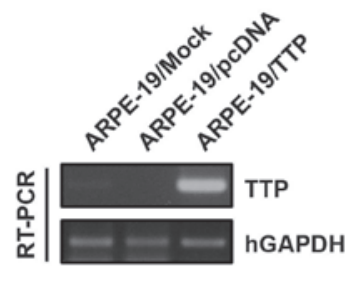

C

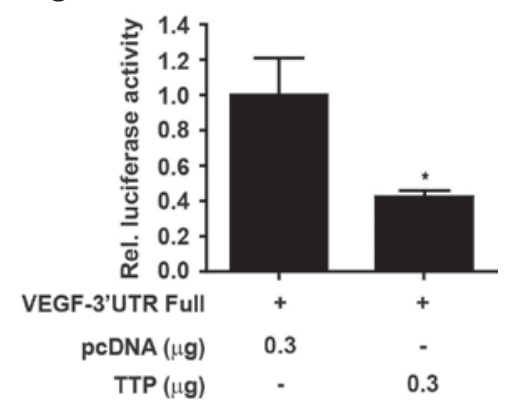

Figure 2. VEGF AREs are essential for the inhibitory effect of TTP. (A) Schematic representation of the luciferase reporter constructs used in the present study. The VEGF mRNA 3'-UTR was cloned downstream of the luciferase reporter gene in the psiCHECK2 vector. The white circles indicate ARE pentamer motifs -(AUUUA)-. (B) To overexpress TTP for the luciferase assay, ARPE-19 cells were transfected with pcDNA6/V5-TTP (ARPE-19/TTP) or empty pcDNA6/V5 vector (ARPE-19/pcDNA). TTP expression was determined by RT-PCR and the expression level of hGAPDH served as a loading control. (C) ARPE-19 cells were co-transfected with pcDNA6/V5-TTP and $0.3 \mu \mathrm{g}$ psiCHECK2 luciferase reporter construct containing the VEGF mRNA 3'-UTR, as presented in (A). The cells were harvested, and luciferase activity was normalized to firefly activity. The results are presented as the mean \pm standard error of the mean of three independent experiments. "P<0.05 vs. ARPE-19/pcDNA. VEGF, vascular endothelial growth factor; ARE, adenosine and uridine rich elements; TTP, tristetraprolin; RT-PCR, reverse trancription-polymerase chain reaction; ORF, open reading frame.

used as negative controls, the AUUUA sequences of the AREs were replaced with AGCA. Cytoplasmic extracts were prepared from pcDNA6/V5-TTP transfected ARPE-19 cells using NE-PER Nuclear and Cytoplasmic Extraction reagent kit (Thermo Fisher Scientific, Inc.). RNA EMSA was performed using the LightShift ${ }^{\mathrm{TM}}$ Chemiluminescent EMSA kit according to the manufacturer's instructions. TTP antibody (T5327) or control (I-5381) antibodies (Sigma-Aldrich; Merck Millipore) were added to the reaction mixtures (1 or $5 \mu \mathrm{g} / \mu \mathrm{l})$. Subsequent to the addition of the antibodies, reaction mixtures were incubated overnight at $4^{\circ} \mathrm{C}$. Images were captured using a LAS 4000 Bioimager (Fujifilm).

Human umbilical vein endothelial cell (HUVEC) tube formation assay. ARPE-19 cells were cultured in DMEM/F12 media containing $0.1 \% \mathrm{FBS}, 100 \mathrm{U} / \mathrm{ml}$ penicillin, and $100 \mu \mathrm{g} / \mathrm{ml}$ streptomycin, and were maintained at $37^{\circ} \mathrm{C}$ and $5 \% \mathrm{CO}_{2}$. The cells were exposed to hypoxic conditions in a hypoxic chamber for $24 \mathrm{~h}$. The conditioned medium (CM) obtained from the
ARPE-19 cells was transferred to HUVECs (PromoCell $\mathrm{GmbH}$, Heidelberg, Germany) that were seeded onto 96-well plates coated with Matrigel ${ }^{\mathrm{TM}}$ at a density of $4 \times 10^{3}$ cells/well. The CM-treated HUVECs were incubated for $48 \mathrm{~h}$, and then the branch numbers were calculated using ImageJ software (imagej.nih.gov).

Statistical analysis. Data are expressed as the mean \pm standard error of the mean. Statistical significance was determined using Student's t-tests (GraphPad Prism, version 5; GraphPad Software, Inc., La Jolla, CA, USA). $\mathrm{P}<0.05$ was considered to indicate a statistically significant difference.

\section{Results}

TTP reduces the expression and secretion levels of hypoxia-induced VEGF. To establish transient expression of TTP, a TTP expression vector (pcDNA6/V5-TTP) was transfected into ARPE-19 cells (ARPE-19/TTP) under 
A

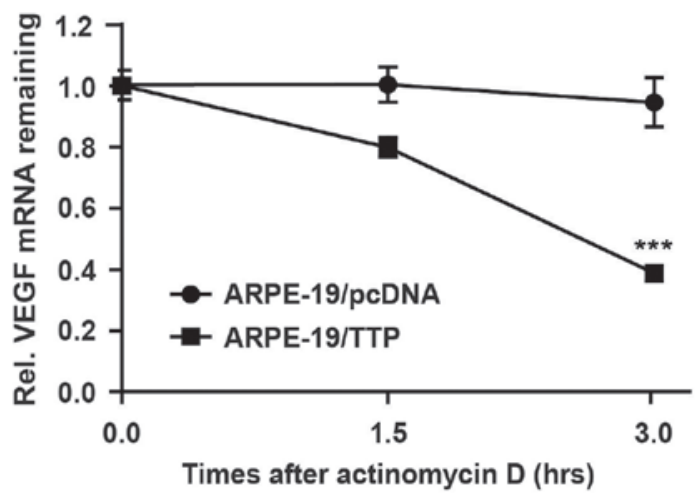

B

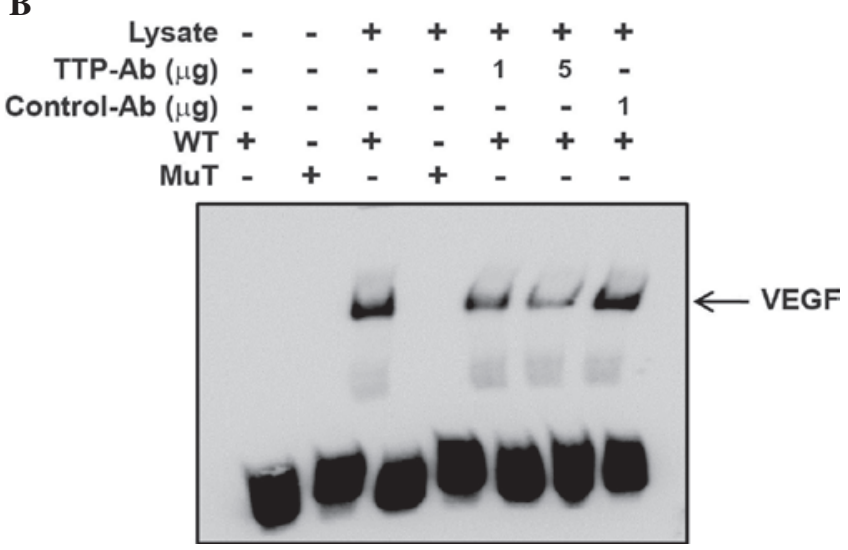

Figure 3. TTP directly binds to VEGF AREs. (A) ARPE-19 cells were transfected with pcDNA6/V5-TTP vector (ARPE-19/TTP) or empty pcDNA6/V5 vector (ARPE-19/pcDNA), and then incubated for $24 \mathrm{~h}$ under hypoxic conditions. The expression level of VEGF mRNA was determined by quantitative polymerase chain reaction at the indicated times following the addition of $5 \mu \mathrm{g} / \mathrm{ml}$ actinomycin D. Data are presented as the mean \pm standard error of the mean of three independent experiments. ${ }^{* * *} \mathrm{P}<0.001 \mathrm{vs}$ ARPE-19/pcDNA cells. (B) An RNA electrophoretic mobility shift assay was performed by mixing cytoplasmic extract containing $1 \mu \mathrm{g}$ total protein from pcDNA6/V5-TTP-transfected ARPE-19 cells with 20 fmol of biotinylated VEGF WT or MuT probes. A TTP-specific or control Ab was added to the reaction mixtures. The binding reactions were then separated by electrophoresis through a $5 \%$ polyacrylamide gel under non-denaturing conditions. The arrows indicate the position of the RNA-protein complex. TTP, tristetraprolin; VEGF, vascular endothelial growth factor; ARE, adenosine and uridine rich elements; Ab, control antibody; WT, wild-type; MuT, mutant.

normoxic conditions. As a negative control, ARPE-19 cells were transiently transfected with empty pcDNA6/V5 vectors. Overexpression of TTP was confirmed by RT-PCR and western blotting (Fig. 1A). The ARPE-19 cells were incubated at $37^{\circ} \mathrm{C}$ in $1 \% \mathrm{O}_{2}$ and $5 \% \mathrm{CO}_{2}$ in order to mimic hypoxia. After $24 \mathrm{~h}$, VEGF expression was induced under hypoxic conditions (Fig. 1B).

A previous study reported that TTP promotes the decay of VEGF transcripts in human colon cancer (23). By contrast, overexpression of TTP in ARPE-19/TTP cells reduced hypoxia-induced VEGF expression (Fig. 1B). Next, it was examined whether overexpression of TTP could reduce the level of VEGF secretion. Secretion of VEGF into the extracellular space was assessed by ELISA. Overexpression of TTP in ARPE-19/TTP cells significantly reduced the level of secreted hypoxia-induced VEGF $(\mathrm{P}<0.01$; Fig. $1 \mathrm{C})$. These results
A

Hypoxia
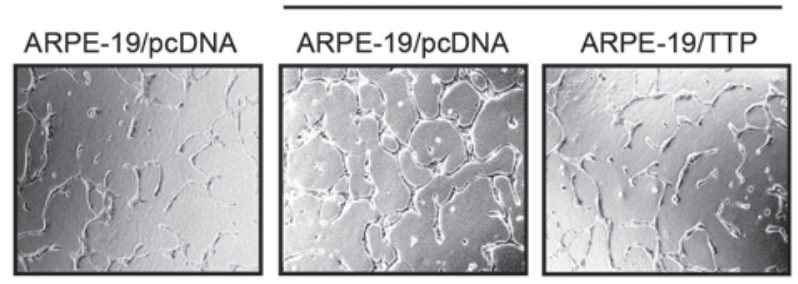

B

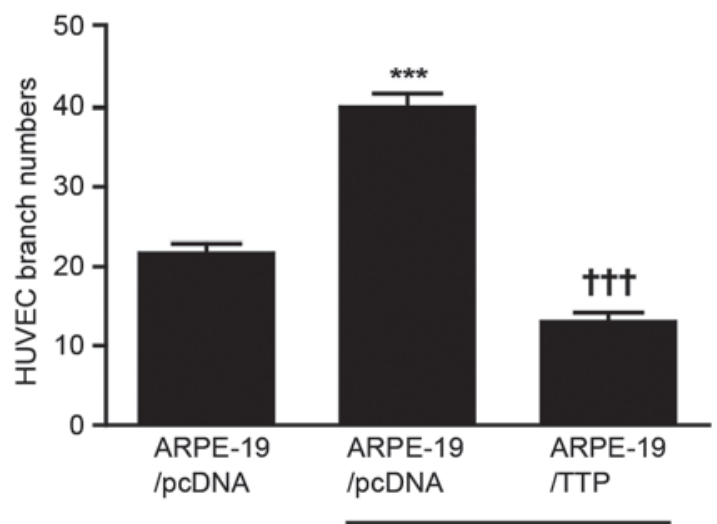

Hypoxia

Figure 4. TTP inhibits neovascularization indirectly. ARPE-19 cells were transfected with pcDNA6/V5-TTP vector (ARPE-19/TTP) or empty pcDNA6/V5 vector (ARPE-19/pcDNA). The cells were then incubated in a hypoxic chamber for $24 \mathrm{~h}$. The CM obtained from the cells was transferred to HUVECs. CM-treated HUVECs were incubated for $48 \mathrm{~h}$. (A) Representative images of HUVECs following incubation with CM obtained from ARPE-19 cells. (B) Branch numbers in HUVECs were calculated using ImageJ software. Data are presented as the mean \pm standard error of the mean of three independent experiments. ${ }^{* * *} \mathrm{P}<0.001 \mathrm{vs.} \mathrm{ARPE-19/pcDNA}$ under normoxia and ${ }^{\dagger} \mathrm{P}<0.001$ vs. ARPE-19/pcDNA under hypoxia. TTP, tristetraprolin; $\mathrm{CM}$, conditioned medium; HUVECs, human umbilical vein endothelial cells.

indicate that overexpression of TTP reduces the expression and secretion levels of hypoxia-induced VEGF.

VEGF AREs are essential for the inhibitory effect of TTP. To determine whether the 3'-UTR of the VEGF mRNA is required for TTP-mediated destabilization, ARPE-19 cells were co-transfected with pcDNA6/V5-TTP and a psiCHECK2 luciferase expression vector containing the VEGF 3'-UTR. The luciferase activity in cells transfected with pcDNA6/V5-TTP was significantly lower than that in cells transfected with pcDNA6/V5 empty vector $(\mathrm{P}<0.05 ;$ Fig. 2$)$. This result suggests that the 3'-UTR of VEGF mRNA is involved in its destabilization via the inhibitory activity of TTP.

TTP binds to VEGF AREs. To investigate whether the reduced expression of VEGF resulted from decay of the VEGF mRNA, the half-life of this mRNA was measured by qPCR in ARPE-19 cells transfected with pcDNA6/V5-TTP (ARPE-19/TTP) or pcDNA6/V5 empty vector (ARPE-19/pcDNA6). The ARPE-19 cells were incubated for $24 \mathrm{~h}$ under hypoxic conditions. Following actinomycin D treatment, the half-life of VEGF mRNA was $1.8 \mathrm{~h}$ in ARPE-19/TTP cells and $6.5 \mathrm{~h}$ in ARPE-19/pcDNA6 cells (Fig. 3A). This result indicates that overexpression of TTP significantly induces the decay of VEGF mRNA $(\mathrm{P}<0.001)$.

To examine whether TTP interacts directly with the AREs in the 3'-UTR of VEGF mRNA, an RNA EMSA was performed 
using biotinylated RNA probes containing the WT or MuT AREs of VEGF. The RNA probes used in EMSA were the same as those used in the luciferase assay. In the MuT RNA probe used as a negative control, AUUUA sequence of the VEGF-ARE-WT was replaced with AGCA. Cytoplasmic extracts prepared from ARPE-19 cells cultured under hypoxic conditions were incubated with biotinylated RNA probes containing the WT or MuT AREs of VEGF 3'UTR. When RNA EMSA was performed using the VEGF-ARE-WT probe, a dominant RNA-protein complex was formed. However, this complex was not formed with VEGF-ARE-MuT probe. Complex formation was reduced in the presence of an anti-TTP antibody (Fig. 3B). Overall, these results suggest that TTP regulates the expression of VEGF mRNA by binding to AREs in its 3'UTR.

TTP inhibits neovascularization indirectly. To determine the effect of TTP overexpression on neovascularization indirectly, a HUVEC tube formation assay was used. ARPE-19 cells transfected with pcDNA6/V5-TTP (ARPE-19/TTP) or pcDNA6/V5 empty vector (ARPE-19/pcDNA6) were incubated at $37^{\circ} \mathrm{C}$ in $1 \% \mathrm{O}_{2}$ and $5 \% \mathrm{CO}_{2}$ to mimic hypoxia. After 24 h, CM from the cells was transferred to HUVECs, which were incubated for $48 \mathrm{~h}$. HUVECs treated with hypoxia CM from ARPE-19/pcDNA6 cells had a larger number of branch points than those treated with normoxia CM from ARPE-19/pcDNA6. However, HUVECs treated with hypoxia CM from ARPE-19/TTP cells had a significantly lower number of branch points than those treated with hypoxia $\mathrm{CM}$ from ARPE-19/pcDNA cells ( $\mathrm{P}<0.001$; Fig. 4A and B). These results suggest that overexpression TTP inhibits neovascularization indirectly.

\section{Discussion}

TTP, a tandem $\mathrm{CCCH}$ zinc-finger RNA-binding protein, regulates the decay of mRNAs that contain multiple AREs (29). The number of published papers discussing TTP has increased gradually since 1990 with >40 TTP-associated papers published in 2012 and interest in this protein is increasing (24). Previous studies demonstrated that TTP induces the decay of ARE-containing mRNAs $(23,30,31)$, including proto-oncogenes and those encoding growth factors (such as VEGF) and proteins involved in inflammation and invasion (32-34). A number of studies have used diverse cells or tissue models to demonstrate that TTP inhibits VEGF production by destabilizing VEGF mRNA, however, to the best of our knowledge, no studies have examined the effects of TTP on the eye or ARPE-19 cells $(25,26,35)$. Thus, the aim of the present study was to investigate the effects of TTP on VEGF mRNA and protein levels in ARPE-19 cells under hypoxic conditions, and to examine the possibility of using TTP as a novel treatment tool for neovascularization and nAMD.

Endogenous expression of TTP was low in ARPE-19 cells under normoxic and hypoxic conditions, whereas VEGF expression was increased under hypoxic conditions. On the other hand, overexpression of TTP reduced the stability of VEGF mRNA and the secretion of VEGF into the extracellular space of ARPE-19 cells under hypoxic conditions. These results suggest that TTP expression is inversely correlated with that of VEGF in ARPE-19 cells, and that TTP does not respond directly to a hypoxic stimulus. Low expression of TTP in ARPE-19 cells under hypoxic conditions resembles TTP in numerous cancer cells. Furthermore, these two states increase the expression of VEGF. These points suggest the possibility of using TTP as a treatment tool for nAMD, in addition to cancer.

A luciferase assay was performed to determine whether the 3'-UTR of VEGF mRNA is required for TTP-mediated destabilization. An RNA EMSA was also conducted to examine whether TTP binds directly to the 3'UTR of this mRNA. As occurs in other cells, TTP in ARPE-19 cells destabilized the VEGF mRNA and bound directly to AREs in its 3'-UTR $(23,24)$. This result indicates that TTP may be used to suppress VEGF in RPE cells when nAMD occurs under hypoxic conditions.

Anti-VEGF antibodies bind directly to VEGFs and render them inactive in the extracellular space $(9,10)$. By contrast, the expression of TTP and destabilization of VEGF mRNAs occurs in the intracellular space. For this reason, gene transfection with a TTP-expressing pcDNA6/V5-HisA vector or adenoviral vectors could be performed in the intracellular space. The effective period of anti-VEGF antibody treatment is $\sim 4$ weeks and aflibercept has a longer duration of effect $(13,15)$. However, the present study did not determine the effective period of TTP-expressing vectors, despite the finding that CM from of TTP-overexpressing ARPE-19 cells suppressed HUVEC tube formation compared with hypoxic CM. Thus, further investigations will be undertaken in the future.

In conclusion, TTP was demonstrated to destabilize the VEGF mRNA in ARPE-19 cells under hypoxic conditions. Furthermore, CM from TTP-overexpressing ARPE-19 cells suppressed tube formation in HUVECs. These findings indicate that regulation of TTP expression may be a promising therapeutic tool for $\mathrm{nAMD}$, although further research is required.

\section{Acknowledgements}

The present study was supported by the Biomedical Research Institute Fund (grant no. GNUHBRIF-2013-0002) of Gyeongsang National University Hospital (Jinju, Korea).

\section{References}

1. Berman K and Brodaty H: Psychosocial effects of age-related macular degeneration. Int Psychogeriatr 18: 415-428, 2006.

2. Chan EC, van Wijngaarden P, Liu GS, Jiang F, Peshavariya H and Dusting GJ: Involvement of Nox2 NADPH oxidase in retinal neovascularization. Invest Ophthalmol Vis Sci 54: 7061-7067, 2013.

3. Engelmann D, Mayoli-Nüssle D, Mayrhofer C, Fürst K, Alla V, Stoll A, Spitschak A, Abshagen K, Vollmar B, Ran S and Pützer BM: E2F1 promotes angiogenesis through the VEGF-C/VEGFR-3 axis in a feedback loop for cooperative induction of PDGF-B. J Mol Cell Biol 5: 391-403, 2013.

4. Ma JF, Von Kalle M, Plautz Q, -M Xu F, Singh L and Wang L: Relaxin promotes in vitro tumour growth, invasion and angiogenesis of human Saos-2 osteosarcoma cells by AKT/VEGF pathway. Eur Rev Med Pharmacol Sci 17: 1345-1350, 2013.

5. Muller YA, Christinger HW, Keyt BA and de Vos AM: The crystal structure of vascular endothelial growth factor (VEGF) refined to 1.93 A resolution: Multiple copy flexibility and receptor binding. Structure 5: 1325-1338, 1997. 
6. Ciulla TA, Danis RP, Criswell M and Pratt LM: Changing therapeutic paradigms for exudative age-related macular degeneration: Antiangiogenic agents and photodynamic therapy. Expert Opin Investig Drugs 8: 2173-2182, 1999.

7. Ogino K, Tsujikawa A, Yamashiro K, Ooto S, Oishi A, Nakata I, Miyake $\mathrm{M}$ and Yoshimura N: Intravitreal injection of ranibizumab for recovery of macular function in eyes with subfoveal polypoidal choroidal vasculopathy. Invest Ophthalmol Vis Sci 54: 3771-3779, 2013.

8. Frampton JE: Ranibizumab: A review of its use in the treatment of neovascular age-related macular degeneration. Drugs Aging 30: 331-358, 2013

9. Scott AW and Bressler SB: Long-term follow-up of vascular endothelial growth factor inhibitor therapy for neovascular age-related macular degeneration. Curr Opin Ophthalmol 24: 190-196, 2013.

10. Jiang S, Park C and Barner JC: Ranibizumab for age-related macular degeneration: A meta-analysis of dose effects and comparison with no anti-VEGF treatment and bevacizumab. J Clin Pharm Ther 39: 234-239, 2014.

11. Binder S: Loss of reactivity in intravitreal anti-VEGF therapy: Tachyphylaxis or tolerance? Br J Ophthalmol 96: 1-2, 2012.

12. Ehlken C, Jungmann S, Bohringer D, Agostini HT, Junker B and Pielen A: Switch of anti-VEGF agents is an option for nonresponders in the treatment of AMD. Eye (Lond) 28: 538-545, 2014

13. Fassnacht-Riederle H, Becker M, Graf N and Michels S: Effect of aflibercept in insufficient responders to prior anti-VEGF therapy in neovascular AMD. Graefes Arch Clin Exp Ophthalmol 252: 1705-1709, 2014

14. Bakall B, Folk JC, Boldt HC, Sohn EH, Stone EM, Russell SR and Mahajan VB: Aflibercept therapy for exudative age-related macular degeneration resistant to bevacizumab and ranibizumab. Am J Ophthalmol 156: 15-22, 2013

15. Schmidt-Erfurth U, Kaiser PK, Korobelnik JF, Brown DM, Chong V, Nguyen QD, Ho AC, Ogura Y, Simader C, Jaffe GJ, et al: Intravitreal aflibercept injection for neovascular age-related macular degeneration: Ninety-six-week results of the VIEW studies. Ophthalmology 121: 193-201, 2014.

16. Fritsche LG, Fariss RN, Stambolian D, Abecasis GR, Curcio CA and Swaroop A: Age-related macular degeneration: Genetics and biology coming together. Annu Rev Genomics Hum Genet 15 151-171, 2014.

17. Xu XD, Li KR, Li XM, Yao J, Qin J and Yan B: Long non-coding RNAs: New players in ocular neovascularization. Mol Bio Rep 41: 4493-4505, 2014.

18. McLaughlin MM, Paglione MG, Slakter J, Tolentino M, Ye L, $\mathrm{Xu}$ CF, Suttle AB and Kim RY: Initial exploration of oral pazopanib in healthy participants and patients with age-related macular degeneration. JAMA Ophthalmol 131: 1595-1601, 2013

19. Arcondéguy T, Lacazette E, Millevoi S, Prats $\mathrm{H}$ and Touriol C: VEGF-A mRNA processing, stability and translation: A paradigm for intricate regulation of gene expression at the post-transcriptional level. Nucleic Acids Res 41: 7997-8010, 2013.

20. Claffey KP, Shih SC, Mullen A, Dziennis S, Cusick JL, Abrams KR, Lee SW and Detmar M: Identification of a human VPF/VEGF 3' untranslated region mediating hypoxia-induced mRNA stability. Mol Biol Cell 9: 469-481, 1998.
21. Levy NS, Chung S, Furneaux H and Levy AP: Hypoxic stabilization of vascular endothelial growth factor mRNA by the RNA-binding protein HuR. J Biol Chem 273: 6417-6423, 1998.

22. Cherradi N, Lejczak C, Desroches-Castan A and Feige JJ: Antagonistic functions of tetradecanoyl phorbol acetate-inducible-sequence $11 \mathrm{~b}$ and HuR in the hormonal regulation of vascular endothelial growth factor messenger ribonucleic acid stability by adrenocorticotropin. Mol Endocrinol 20: 916-930, 2006

23. Lee HH, Son YJ, Lee WH, Park YW, Chae SW, Cho WJ, Kim YM, Choi HJ, Choi DH, Jung SW, et al: Tristetraprolin regulates expression of VEGF and tumorigenesis in human colon cancer. Int J Cancer 126: 1817-1827, 2010.

24. Brooks SA and Blackshear PJ: Tristetraprolin (TTP): Interactions with mRNA and proteins, and current thoughts on mechanisms of action. Biochim Biophys Acta 1829: 666-679, 2013.

25. Cha HJ, Lee HH, Chae SW, Cho WJ, Kim YM, Choi HJ, Choi DH, Jung SW, Min YJ, Lee BJ, et al: Tristetraprolin downregulates the expression of both VEGF and COX-2 in human colon cancer. Hepatogastroenterology 58: 790-795, 2011.

26. Brennan SE, Kuwano Y, Alkharouf N, Blackshear PJ, Gorospe $\mathrm{M}$ and Wilson GM: The mRNA-destabilizing protein tristetraprolin is suppressed in many cancers, altering tumorigenic phenotypes and patient prognosis. Cancer Res 69: 5168-5176, 2009

27. Lee HH, Vo MT, Kim HJ, Lee UH, Kim CW, Kim HK, Ko MS, Lee WH, Cha SJ, Min YJ, et al: Stability of the LATS2 tumor suppressor gene is regulated by tristetraprolin. J Biol Chem 285: 17329-17337, 2010

28. Schmittgen TD and Livak KJ: Analyzing real-time PCR data by the comparative C(T) method. Nat Protoc 3: 1101-1108, 2008

29. Baou M, Jewell A and Murphy JJ: TIS11 family proteins and their roles in posttranscriptional gene regulation. J Biomed Biotechnol 2009: 634520, 2009.

30. Carballo E, Lai WS and Blackshear PJ: Feedback inhibition of macrophage tumor necrosis factor-alpha production by tristetraprolin. Science 281: 1001-1005, 1998.

31. Hau HH, Walsh RJ, Ogilvie RL, Williams DA, Reilly CS and Bohjanen PR: Tristetraprolin recruits functional mRNA decay complexes to ARE sequences. J Cell Biochem 100: 1477-1492, 2007.

32. Nanbu R, Menoud PA and Nagamine Y: Multiple instability-regulating sites in the 3' untranslated region of the urokinase-type plasminogen activator mRNA. Mol Cell Biol 14: 4920-4928, 1994.

33. Roldan AL, Cubellis MV, Masucci MT, Behrendt N, Lund LR, Danø K, Appella E and Blasi F: Cloning and expression of the receptor for human urokinase plasminogen activator, a central molecule in cell surface, plasmin dependent proteolysis. EMBO J 9: 467-474, 1990.

34. Fini ME,PlucinskaIM,Mayer AS, Gross RH and BrinckerhoffCE: A gene for rabbit synovial cell collagenase: Member of a family of metalloproteinases that degrade the connective tissue matrix. Biochemistry 26: 6156-6165, 1987.

35. Hacker C, Valchanova R, Adams S and Munz B: ZFP36L1 is regulated by growth factors and cytokines in keratinocytes and influences their VEGF production. Growth Factors 28: 178-190, 2010. 